\title{
EVALUASI POLA PENGGUNAAN ANTIBIOTIK DENGAN BERBAGAI PENYAKIT DI RUMAH SAKIT UMUM IMELDA PEKERJA INDONESIA MEDAN
}

\author{
Dina Maya Syari ${ }^{1}$, Nurviah ${ }^{2}$ \\ Universitas Imelda Medan
}

\begin{tabular}{l}
\hline \hline Article Info \\
\hline Article history: \\
Received Mar 4, 2021 \\
Revised Mar 24, 2021 \\
Accepted Mar 25, 2021 \\
\hline
\end{tabular}

\section{Keywords:}

Infection

Oral Antibiotics

Formulary

\begin{abstract}
The hospital is a professional health care institution in providing health professionals to provide patient diagnosis and therapy. Antibiotic prescribing aims to treat infectious diseases and prevent infection in patients who are at high risk for infection. Infectious diseases are a major problem that occurs in developing countries due to the presence of pathogenic microorganisms in the human body. Antibiotic therapy given to inpatients at the Imelda Indonesian Workers General Hospital in Medan, such as the $\beta$-lactam group, cephalosporins, macrolides, quinolones and thiamphenicol. The highest use of oral antibiotic therapy in 2018 was amoxicillin and levofloxacin. This study was an observational study conducted retrospectively and analyzed using descriptive statistical methods. Analysis with statistical methods only deals with how to describe or provide information about data, circumstances, and phenomena so that they are easy to understand. Data processing used the SPSS 21 program. The results showed that the most widely used oral antibiotics were cefadroxil $83(18.5 \%)$ and low INH 1 antibiotics $(0.2 \%)$. The use of oral antibiotics in inpatients at Imelda General Hospital Indonesian workers in 2019 are in accordance with the Hospital formulary.
\end{abstract}

This is an open access article under the CC BY-SAlicense.

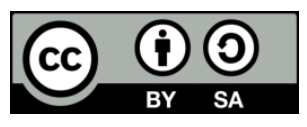

Corresponding Author:

Dina Maya Syari,

Program Studi S1 Farmasi,

Universitas Imelda Medan,

Jl. Bilal No. 52 Kelurahan Pulo Brayan Darat I Kecamatan Medan Timur, Medan - Sumatera Utara.

Email: dinamayasyari.dms@gmail.com

\section{INTRODUCTION}

Penyakit infeksi merupakan masalah utama yang terjadi di negara berkembang disebabkan adanya mikroorganisme patogen pada tubuh manusia (Zen, M., 2017; Mutsaqof dkk, 2015). Setiap tahun penyakit infeksi dapat menyebabkan kematian lebih dari 13 juta jiwa, penyakit infeksi pada saluran pernapasan sebesar 4,3 juta dan 2,9 juta akibat infeksi saluran cerna (Cohen, M. L. 2000; Mabey et al., 2004). Penyakit infeksi yang terjadi setelah pembedahan dapat terjadi antara 1,2\% hingga 23,6\% dalam 100 prosedur bedah (WHO, 2011).

Rumah sakit merupakan institusi perawatan kesehatan profesional menyediakan tenaga ahli kesehatan untuk memberikan diagnosa dan terapi pasien (Lantang dkk, 2012). Pemberian antibiotik intensif 
terjadi di dalam rumah sakit (Isturiz et al., 2000). Peresepan antibiotik bertujuan mengatasi penyakit infeksi dan mencegah infeksi pada pasien yang beresiko tinggi mengalami infeksi seperti pasien bedah (Permenkes RI, 2015). Menurut penelitian (Pebriana P dkk, 2018), antibiotik paling banyak digunakan adalah antibiotik golongan penisilin $43,77 \%$, sefalosporin $26,69 \%$, dan quinolon $7,47 \%$. Ketepatan penggunaan antibiotik merupakan aspek penting untuk efektivitas dan keamanan terapi pada pasien, terutama pasien dengan fisiologi dan farmakologi berbeda (Monica dkk., 2018). Terapi antibiotik yang diberikan pada pasien rawat inap Rumah Sakit Umum Imelda Pekerja Indonesia Medan yaitu golongan $\beta$-laktam, sefalosporin, makrolida, quinolon dan tiamphenicol. Penggunaan terapi antibiotik oral terbanyak pada tahun 2018 adalah amoxicillin dan levofloxacin.

Berdasarkan uraian diatas, peneliti melakukan evaluasi pola penggunaan antibiotik dengan berbagai penyakit di Rumah Sakit Umum Imelda Medan pada tahun 2019. Penelitian ini dilakukan untuk melihat penggunaan antibiotik yang paling banyak di Rumah Sakit Imelda Medan. Adapun tujuan penelitian ini adalah untuk mengetahui kesesuaian penggunaan antibiotik dengan formularium Rumah Sakit Umum Imelda Pekerja Indonesia Medan tahun 2019.

\section{RESEARCH METHOD}

Sampel penelitian yaitu seluruh data rekam medik pasien yang menggunakan antibiotik oral dengan menggunakan metode purposive sampling sesuai dengan kriteria inklusi. Sampel dalam penelitian ini sebanyak 350 sampel. Pengumpulan sampel dalam penelitian ini menggunakan rumus Slovin sebagai berikut: $\mathrm{n}=\frac{\mathrm{N}}{1+\mathrm{N}(\mathrm{e})^{2}}$

Keterangan:

$\mathrm{n}$ : Sampel yang dicari

N: Populasi

E : Besar kesalahan $(5 \%)$

Penelitian ini dilakukan di Rumah Sakit Umum Imelda Pekerja Indonesia Medan, Jalan Bilal no. 24 Pulo Brayan Darat 1 Medan Timur. Rumah Sakit Umum Imelda Pekerja Indonesia Medan digunakan sebagai objek penelitian karena Rumah Sakit Umum Imelda Pekerja Indonesia Medan setiap tahunnya melakukan evaluasi penggunaan antibiotik. Jangka waktu penelitian ini selama Januari s/d Desember 2019.

Pengumpulan data menggunakan metode statistik deskriptif, teknik pengumpulan data yang dilakukan dengan cara penelusuran literatur. Penelusuran literatur adalah cara pengumpulan data dengan menggunakan sebagian atau seluruh data yang ada. Pengumpulan data dilakukan dengan cara pengambilan data rekam medik pasien rawat inap di Rumah Sakit Umum Imelda Pekerja Indonesia Medan. Data rekam medik dilakukan seleksi berdasarkan penggunaan antibiotik secara oral.

Setelah data terkumpul, maka langkah selanjutnya adalah melakukan analisa data. Analisa data yaitu proses pengaturan data dalam keadaan suatu pola, kategori, atau persentase. Analisis dalam penelitian ini diolah dengan bantuan aplikasi pengolah data SPSS (Statistical product and service solution) 21.0 for windows. Data yang diperoleh di analisisa secara univariat untuk menggambarkan karakteristik responden.

\section{RESULTS AND ANALYSIS \\ Karakteristik Subjek Penelitian}

Berdasarkan penelitian yang dilakukan pada pasien rawat inap di Rumah Sakit Umum Imelda pekerja Indonesia Medan, presentase jumlah penggunaan antibiotik oral berdasarkan usia dapat dilihat pada Tabel 1 berikut ini:

Tabel 1. Karakteristik Pasien Berdasarkan Usia
\begin{tabular}{cc}
\hline Umur (Tahun) & Persentase (\%) \\
\hline 1 & 5,7 \\
\hline 3 & 2,0 \\
\hline 6 & 2,0 \\
\hline 19 & 3,1 \\
\hline 20 & 3,1 \\
\hline 21 & 4,0 \\
\hline 23 & 2,9 \\
\hline 24 & 2,3 \\
\hline 25 & 2,3 \\
\hline 26 & 2,3 \\
\hline 27 & 2,0 \\
\hline
\end{tabular}




\begin{tabular}{ll}
\hline 29 & 3,7 \\
\hline 31 & 3,1 \\
\hline 32 & 2,0 \\
\hline 33 & 2,3 \\
\hline 34 & 2,3 \\
\hline 38 & 2,3 \\
\hline 46 & 2,0
\end{tabular}

Berdasarkan tabel diatas dapat disimpulkan bahwa dari 350 pasien yang paling banyak menggunakan antibiotik oral adalah pasien berusia 1 tahun sebanyak 20 (4,5\%) .

\section{Karakteristik Pasien Berdasarkan Jenis Kelamin}

Tabel 2. Karakteristik Pasien Berdasarkan Jenis Kelamin

\begin{tabular}{ccc}
\hline Jenis Kelamin & Jumlah & Persentase (\%) \\
\hline Laki-laki & 148 & 42,3 \\
\hline Perempuan & 202 & 57,7 \\
\hline Jumlah & $\mathbf{3 5 0}$ & $\mathbf{1 0 0}$ \\
\hline
\end{tabular}

Berdasarkan tabel diatas, dapat dilihat bahwa jenis kelamin yang paling banyak mendapat terapi antibiotik oral adalah wanita 202 pasien (45\%), sedangkan laki-laki 148 pasien (33\%).

\section{Diagnosa Pasien Rawat Inap}

Diagnosa pasien rawat inap di Rumah Sakit Umum Imelda Pekerja Indonesia memiliki berbagai jenis diagnosa, terdapat lebih dari satu diagnosa yang diderita pasien rawat inap. Diagnosa pasien rawat inap yang menggunakan antibiotik oral dapat dilihat pada gambar 1 yang terdiri dari diangnosa tunggal sebanyak $131(29,2 \%)$, pesien dengan dua diagnosa $98(21,8 \%)$, pasien dengan tiga dignosa $46(10,2 \%)$, pasien dengan diagnosa empat $36(8,0 \%)$, pasien dengan diagnosa lima atau lebih $38(8,5 \%)$.

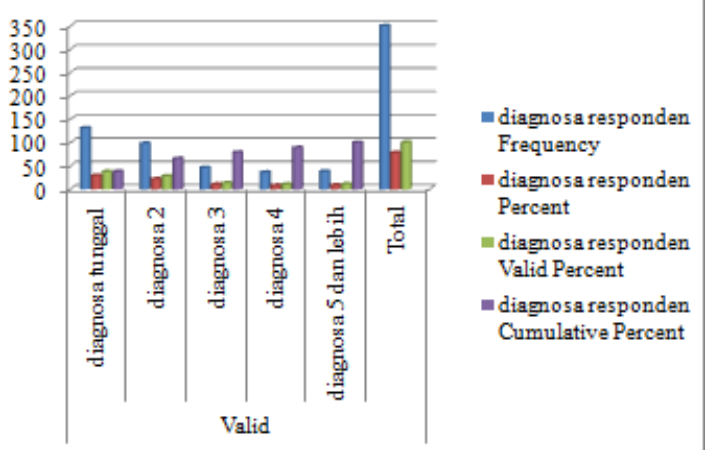

Gambar 1. Diagnosa Pasien Rawat Inap

\section{Persentase Penggunaan Antibiotik Oral}

Total penggunaan antibiotik oral pada pasien rawat inap di Rumah Sakit Umum Imelda Pekerja Indonesia tahun 2019 yang paling banyak pada bulan Maret 427, April 372, Februari 359, Januari 194, Juli 193, Agustus 193, Mei 187, September 181, November 176, Oktober 175, dan Desember 162. Hal ini dapat dilihat pada Gambar 2.

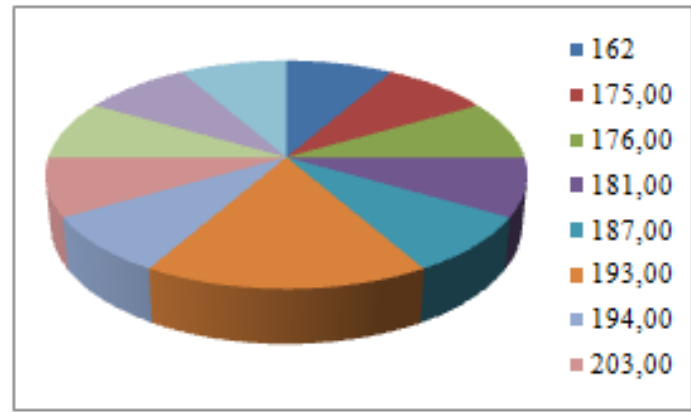

Gambar 2. Persentasi Penggunaan Antibiotik Oral Tahun 2019

Penggunaan antibiotik oral sebagai terapi di Rumah Sakit Umum Imelda Pekerja Indonesia yang paling banyak digunakan adalah cefadroxil $83(18,5 \%)$ dan antibiotik sedikit INH $1(0,2 \%)$ seperti pada gambar 3 . 


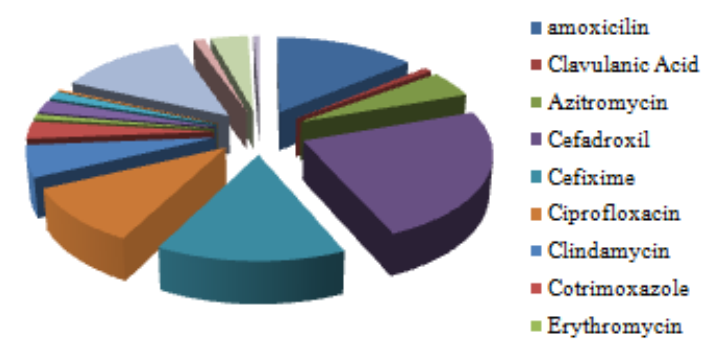

Gambar 3. Persentase Penggunaan Jenis Antibiotik Oral

Tabel 3. Penggunaan Antibiotik Oral

\begin{tabular}{ccc}
\hline Penggunaan antibiotik & Jumlah & Persentase (\%) \\
\hline Tunggal & 278 & 79,9 \\
\hline Ganda & 57 & 16,4 \\
\hline 3 atau lebih & 25 & 3,7 \\
\hline Jumlah & $\mathbf{3 5 0}$ & $\mathbf{1 0 0}$
\end{tabular}

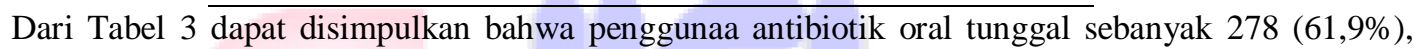
kemudian antibiotik oral ganda $57(12,7 \%)$, dan antibiotik oral yang digunakan 3 atau lebih sebanyak 13 $(2,9 \%)$.

\section{Formularium Rumah Sakit}

Penggunaan antibiotik Oral pada pasien rawat inap di Rumah Sakit Umum Imelda Pekerja Indonesia sudah sesuai dengan formularium Rumah Sakit. Kesesuaian tersebut dapat lihat dari antibiotik oral yang diberikan kepada pasien rawat inap sebagai terapi. Formularium Rumah Sakit merupakan daftar obat yang telah disepakati yang disusun oleh Tim Farmasi dan Terapi.

\section{CONCLUSION}

1. Antibiotik oral yang paling banyak digunakan di Rumah Sakit Umum Imelda Pekerja Indonesia Medan tahun 2019 adalah cefadroxil $83(18,5 \%)$ dan antibiotik sedikit INH $1(0,2 \%)$.

2. Penggunaan antibiotik oral pada pasien rawat inap di Rumah Sakit umum Imelda Pekerja Indonesi tahun 2019 sudah sesuai dengan formularium Rumah Sakit. Kesesuaian tersebut dapat lihat dari antibiotik oral yang diberikan kepada pasien rawat inap sebagai terapi.

\section{REFERENCES}

Ansel, H. C. 1989. Pengantar Bentuk Sediaan Farmasi Edisi ke-4. Jakarta: UI Press.

Cohen, M. L. 2000. Changing Patterns of Infection Disease. USA: Nature. Doi: 10.1038.

Darmadi. 2008. Infeksi Nosokomial "Problematika dan Pengendaliannya”. Jakarta: Salemba Medika. Hal.1, $8,11,12$.

Direktorat Jenderal Bina Kefarmasian Dan Alat Kesehatan. 2010. Pedoman Penyusunan Formularium Rumah Sakit. Jakarta: JICA.

Endarti, D. 2007. Kapita Selekta Dispensing I" Untuk Pelayanan Kefarmasian. Edisi Revisi. Yogyakarta: Hal. 30.

Istiantoro, Y. H. Dan Gan, V. H. S. 2008. Farmakologi dan Terapi. Edisi5. Jakarta: Balai Penerbit FKUI. Hal. 674, 678, 680, 681, 683, 685 .

Isturiz, R. E. and Carbon, C. 2000. Antibiotic Use in Developing Countries. Chicago: The University of Chicago Press. Hal. 395. Doi : 10.1086/501780.

Katzung, B.G. 1997. Farmakologi Dasar dan Klinik Edisi VI. Jakarta: EGC. Hal.702,705, 708, 711, 712, 716,717

Lantang, D., dan Paiman, D. 2012. Bakteri Aerob Penyebab Infeksi Nosokomial di Ruang Bedah. Papua: Jurnal Biologi Papua. ISSN : 2086-3314.

Mabey, D., Peeling, R. W., Ustianowski, A., and Perkins, M. D. 2004. Diagnostics for The Developing World. Nature Reviews Microbiology. P. 231. Doi : 10.1038/nrmicro841.

Monica, S., Irawati, S., Setiawan, E. 2018. Kajian Penggunaan, Ketepatan, dan Biaya Antibiotik pada Pasien Rawat Inap Anak di Sebuah Rumah Sakit Umum di Surabaya. Jurnal Farmasi Klinik Indonesia. Hal. 194. Doi. 10.15416/ijcp.2018.7.3.194 
Mutsaqof, A. A. N., Wiharto, S.T .M. Kom., dan Suryani, E. S.Si. M.Kom. 2015. Sistem Pakar untuk Mendiagnosis Penyakit Infeksi Menggukan Forward Chaining. Surakarta. Jurnal ITSMART. ISSN: 2301-7201.

Nasution, L. M. 2017. Statistik Deskriptif. Jurnal Hikmah. Hal. 49. ISSN: 1829-8419.

Pebriana, P. Puspitaningtyas, P. H., dan Sasongko, H. 2018. Penilaian Pola Penggunaan Obat Berdasarkan Indikator Peresepan WHO di RSUD Ir Soekarno Sukoharjo. Jurnal Stikes Borneo Lestari. Hal 27.ISSN. 2541-3651.

Permenkes RI. 2010. Pedoman Pembinaan Dan Pengawasan Penggunaan Obat Generik Di Fasilitas Pelayanan Kesehatan Pemerintah. Jakarta: Menkes RI.

Permenkes RI No. 8. 2015. Program Pengendalian Resistensi Antimikroba di Rumah Sakit. Jakarta: Menkes RI.

Permenkes RI No. 72. 2016. Standar Pelayanan Kefarmasian Di Rumah Sakit. Jakarta: Menkes RI.

Permenkes RI No. 27. 2017. Pedoman Pencegahan dan Pengendalian Infeksi di Fasilitas Pelayanan Kesehatan. Jakarta: Berita Negara Republik Indonesia.

Prabu, B. D. R. 1991. Penyakit-Penyakit Infeksi Umum Jilid 1. Jakarta: Widya Medika. Hal.35, 37.

Pratiwi, Sylvia T. 2008. Mikrobiologi Farmasi. Jakarta: Penerbit Erlangga. Hal. 150.

Pratiwi, R. H. 2017. Mekanisme Pertahanan Bakteri Patogen Terhadap Antibiotik. Jakarta. Jurnal Pro-Life. Hal.423 dan 424. ISSN e-Journal 2579-7557.

Priyanto. 2010. Farmakologi Dasar untuk Mahasiswa Farmasi dan Keperawatan Edisi II. Jawa Barat: Leskonfi. Hal. 90, 91, 92,93, 94. ISBN 978-979-17202-1-2.

Septiari, B. B. 2012. Infeksi Nosokomial. Yogyakarta: Nuha Medika. Hal.2, 18, 24, 25, 39, 46, 47.

Setiabudy, R. 2008. Farmakologi dan Terapi edisi 5. Jakarta: Balai Penerbit FKUI. Hal.585, 586, 588, 589.

Syamsuni, A. 2006. Ilmu Resep. Jakarta: EGC. Hal.54 dan 165.

Tjay, Tan H., Dan Rahardja, Kirana Drs. 2002. Obat-Obat Penting Khasiat, penggunaan, dan Efek Samping Edisi 5. Jakarta: Gramedia. Hal.63, 64, 66, 67, 68, 69, 71.

WHO. 2011. Report on The Burden of Endemic Health Care-Associated Infection worldwide. Switzerland: P. 3.

Zen, M. 2017. Sistem Pakar Portal Penyakit Infeksi. Jakarta. Jurnal Teknologi. ISSN 2088-3315. 